\title{
Solid state reaction and operational stability of ruthenium Schottky contact-on-6H-SiC under argon annealing
}

\author{
Kinnock V. Munthali, ${ }^{\mathrm{a}, \mathrm{b}}$ Chris Theron ${ }^{\mathrm{a}}$, F. Danie Auret ${ }^{\mathrm{a}}$, Sergio M.M. Coelho ${ }^{\mathrm{a}}$, Eric Njoroge \\ ${ }^{a}$ Department of Physics, University of Pretoria, Pretoria 0002, South Africa
}

Phone: +27 124204777

Fax: +27123625288

Email: kvmunthali@gmail.com

${ }^{\mathrm{b}}$.Department of Mathematics, Science and Sports Education

University of Namibia, HP Campus, P/Bag 5507, Oshakati, Namibia

Corresponding author: Kinnock V. Munthali ,Email: kvmunthali@gmail.com

\begin{abstract}
Thin films of ruthenium-on-6-hexagonal silicon carbide $(6 \mathrm{H}-\mathrm{SiC})$ were analysed by Rutherford backscattering spectroscopy (RBS) at various annealing temperatures. Some thin film samples were also analysed by scanning electron microscope (SEM). RBS analysis indicated minimal element diffusion, and formation of ruthenium oxide after annealing at $500{ }^{\circ} \mathrm{C}$. Large scale diffusion of ruthenium $(\mathrm{Ru})$ was observed to commence at $700{ }^{\circ} \mathrm{C}$. The SEM images indicated that the as-deposited Ru was disorderly and amorphous. Annealing of the thin film improved the grain quality of Ru. The fabricated Ru-6H-SiC Schottky barrier diodes (SBD) with nickel ohmic contacts showed excellent rectifying behaviour and linear capacitance-voltage characteristics up to an annealing temperature of $900{ }^{\circ} \mathrm{C}$. The SBDs degraded after annealing at $1000{ }^{\circ} \mathrm{C}$. The degradation of the SBDs is attributed to the inter-diffusion of $\mathrm{Ru}$ and $\mathrm{Si}$ at the Schottky-substrate interface.
\end{abstract}

\section{Keywords}

Rutherford backscattering spectroscopy, scanning electron microscope, diffusion, Schottky barrier diodes, ruthenium, ruthenium oxide, $6 \mathrm{H}-\mathrm{SiC}$, nickel. 


\section{Introduction}

Silicon carbide ( $\mathrm{SiC}$ ), when compared with silicon, has superior qualities of a large band gap, high breakdown electric field, high thermal conductivity, high saturation carrier velocity, and high mechanical strength. It is for these reasons that there is renewed interest among researchers to produce SiC-based diodes and electronic devices that can operate in extreme temperature conditions such as avionics, microwaves, high voltage switching, deep sea wells and space rockets. There are several polytypes of SiC, but the two main polytypes used for semiconductor device fabrication are 4-hexagonal $\mathrm{SiC}(4 \mathrm{H}-\mathrm{SiC})$ and 6-hexagonal $\mathrm{SiC}(6 \mathrm{H}-\mathrm{SiC}) . \mathrm{SiC}$ 's properties of a high breakdown electric field $\left(2.2 \times 10^{6} \mathrm{~V} / \mathrm{cm}\right.$ for $4 \mathrm{H}-\mathrm{SiC}, 2.4 \times 10^{6} \mathrm{~V} / \mathrm{cm}$ for $\left.6 \mathrm{H}-\mathrm{SiC}\right)$ and high thermal conductivity $(4.9 \mathrm{~W} / \mathrm{cmK}$ for $6 \mathrm{H}$ and $4 \mathrm{H})$ are ideal for high voltage, high power and high packing density of discrete electronic devices [1]. Ruthenium $(\mathrm{Ru})$ has a high melting point $\left(2250^{\circ} \mathrm{C}\right)$, high chemical stability, low electrical resistance, and high mechanical resistance to abrasion and fatigue [2]. These properties make Ru a good candidate as a Schottky contact for high temperature operating Schottky barrier diodes (SBDs). However there has been limited literature $[1,2,3,4,5,6,7]$ on the performance of $\mathrm{Ru}$ on SiC Schottky diodes, and the limited literature has not delved much into the details of the solid state reaction of $\mathrm{Ru}$ with $\mathrm{SiC}$ during the annealing process.

In this experiment the $\mathrm{Ru}-6 \mathrm{H}-\mathrm{SiC}$ SBDs with nickel back ohmic contacts were annealed in argon at various temperatures. The data on variation of SBH, ideality factor, reverse-saturation current and series resistance with annealing temperature were obtained from the current-voltage (IV) and capacitance-voltage (CV) characteristics of the diode. For microstructure characterisation of the Schottky contact, a thin film of $\mathrm{Ru}$ on $6 \mathrm{H}-\mathrm{SiC}$ was analysed with Rutherford Backscattering Spectrometry (RBS) and scanning electron microscope (SEM) at various annealing temperatures.

\section{Experimental Method}

The preparation of metal-SiC interfaces has a critical effect on the physical, chemical and electrical behaviour of the contact, and on its reliability. Experiments have shown that the electrical performances of Schottky contacts on $\mathrm{SiC}$, in addition to physical and chemical properties are strongly dependent on the quality of the metalsemiconductor interface and the surface preparation prior to metallization [8].

The n-type $6 \mathrm{H}-\mathrm{SiC}$ from Cree Research was prepared for metallization by degreasing, using an ultra-sonic bath for a period of $5 \mathrm{~min}$ for each step, in trichloroethylene, acetone, methanol, and deoxidizing $10 \% \mathrm{HF}$. The 
sample was finally rinsed in deionised water and then dried with nitrogen before being loaded into the vacuum chamber where 200nm of nickel (Ni) was deposited by vacuum resistive evaporation. The sample was then annealed in a nitrogen atmosphere at a temperature of $1000^{\circ} \mathrm{C}$ for 1 min to make the contact ohmic. The annealed sample was chemically cleaned again in trichloroethylene, acetone and methanol, and deionised water before a $50 \mathrm{~nm}$ thick of Ru was deposited by e-beam through a metal contact mask at $10^{-6} \mathrm{mbar}$ pressure. The Ru film thickness was monitored by Infincon meter until the required thickness was obtained. A number of Schottky contacts of $0.6 \mathrm{~mm}$ in diameter were fabricated. The SBDs produced were then annealed in argon.

The sample for microstructure characterisation was made by depositing a $50 \mathrm{~nm}$ film of $\mathrm{Ru}$ on $6 \mathrm{H}-\mathrm{SiC}$. Before deposition of the $\mathrm{Ru}$ film, the $6 \mathrm{H}-\mathrm{SiC}$ sample was cleaned through the steps mentioned in the paragraph immediately above.

The Ru-6H-SiC Schottky diodes were annealed in argon for a period of $15 \mathrm{~min}$ at temperatures ranging from $100^{\circ} \mathrm{C}$ to $1000^{\circ} \mathrm{C}$. Full IV and $\mathrm{CV}$ characterisation of the diodes was performed at an ambient temperature of $24^{\circ} \mathrm{C}$ after each annealing process, using a 4140B PA meter /DC voltage source by Hewlett Packard, which was interfaced to a LabVIEW-operated computer. The CV measurements were done at a frequency of $1 \mathrm{MHz}$. Both the IV and CV measurement data were automatically saved on the computer by LabVIEW.

The sample for microstructure characterisation was also annealed in argon at various temperatures, and RBS analysis was performed at room temperature after each annealing process. SEM images of the as-deposited thin film of $\mathrm{Ru}-6 \mathrm{H}-\mathrm{SiC}$ and the one annealed at $500{ }^{\circ} \mathrm{C}$ were also taken.

\section{Experimental Results and Discussion}

RBS analysis of as-deposited $\mathrm{Ru}-6 \mathrm{H}-\mathrm{SiC}$ thin film shows a pure film of $\mathrm{Ru}$ on the $\mathrm{SiC}$ (Fig. 1). The RBS spectra for samples annealed up to $400{ }^{\circ} \mathrm{C}$ (not shown) are similar to the as-deposited spectrum. Oxidation of Ru is observed at an annealing temperature of $500{ }^{\circ} \mathrm{C}$ (Fig. 2) as evidenced by a pronounced oxygen peak at channel 182. Diffusion of $\mathrm{Ru}$ into the $\mathrm{SiC}$ layer is seen to commence at $700{ }^{\circ} \mathrm{C}$ (Fig. 3), as indicated by the widening of the base width of the Ru signal. There is increased oxidation of $\mathrm{Ru}$ at this temperature as demonstrated by a 


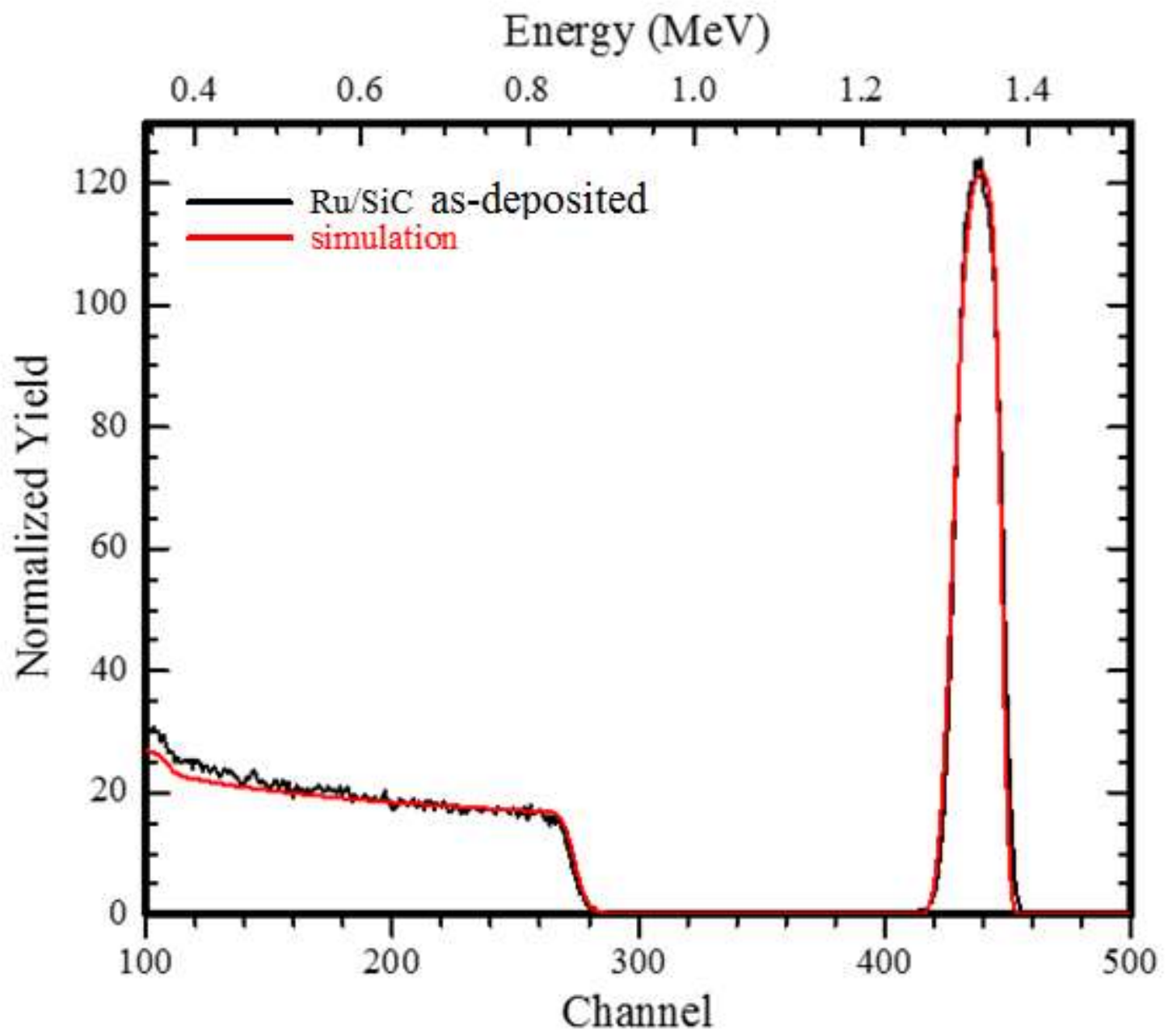

Fig. 1. RBS spectrum of thin film of as-deposited Ru-6H-SiC obtained by using $1.6 \mathrm{MeV}$ helium ions. 


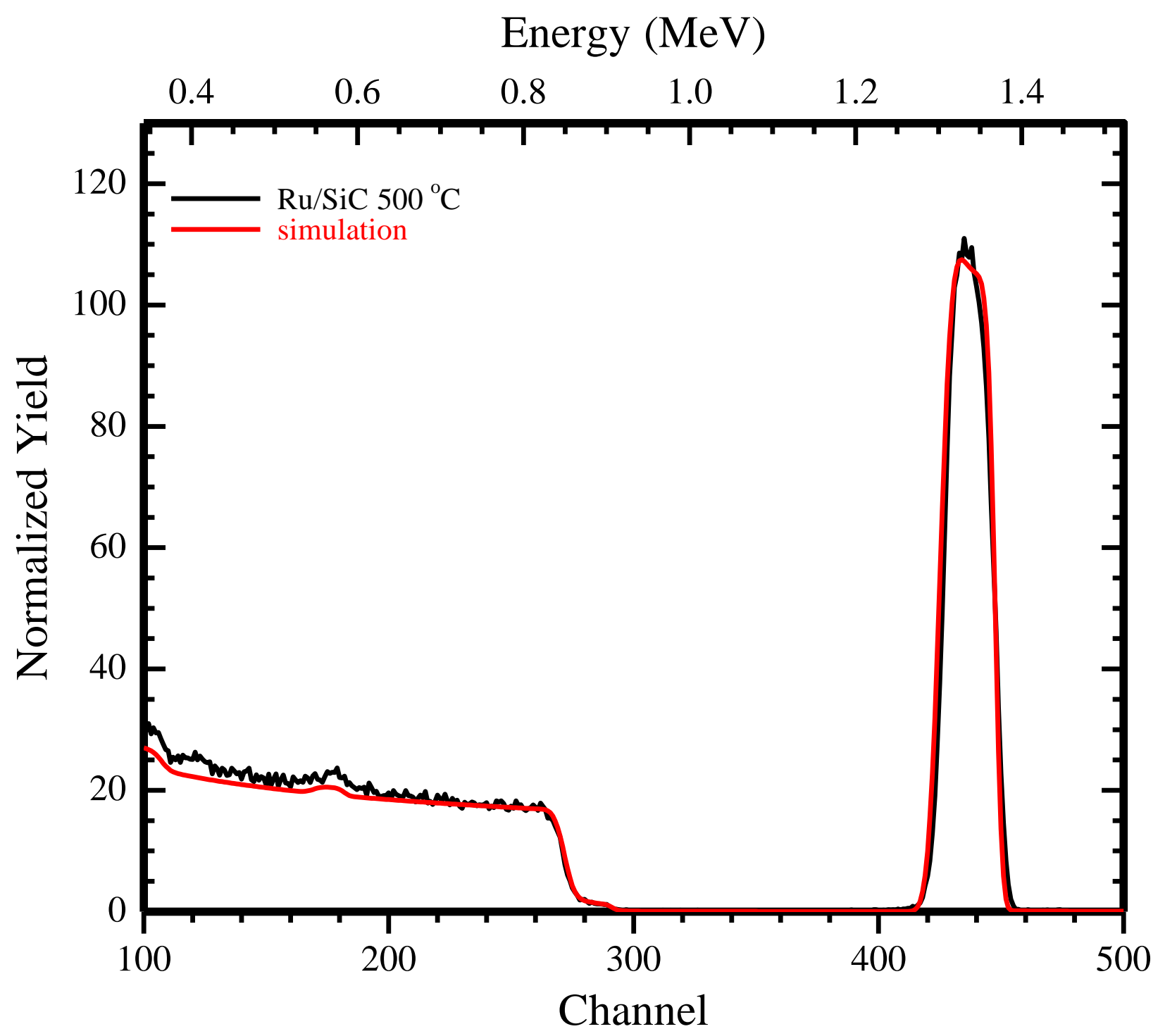

Fig. 2. RBS spectrum of thin film of Ru- $6 \mathrm{H}-\mathrm{SiC}$ annealed in argon at $500{ }^{\circ} \mathrm{C}$ obtained by using $1.6 \mathrm{MeV}$ helium ions. 


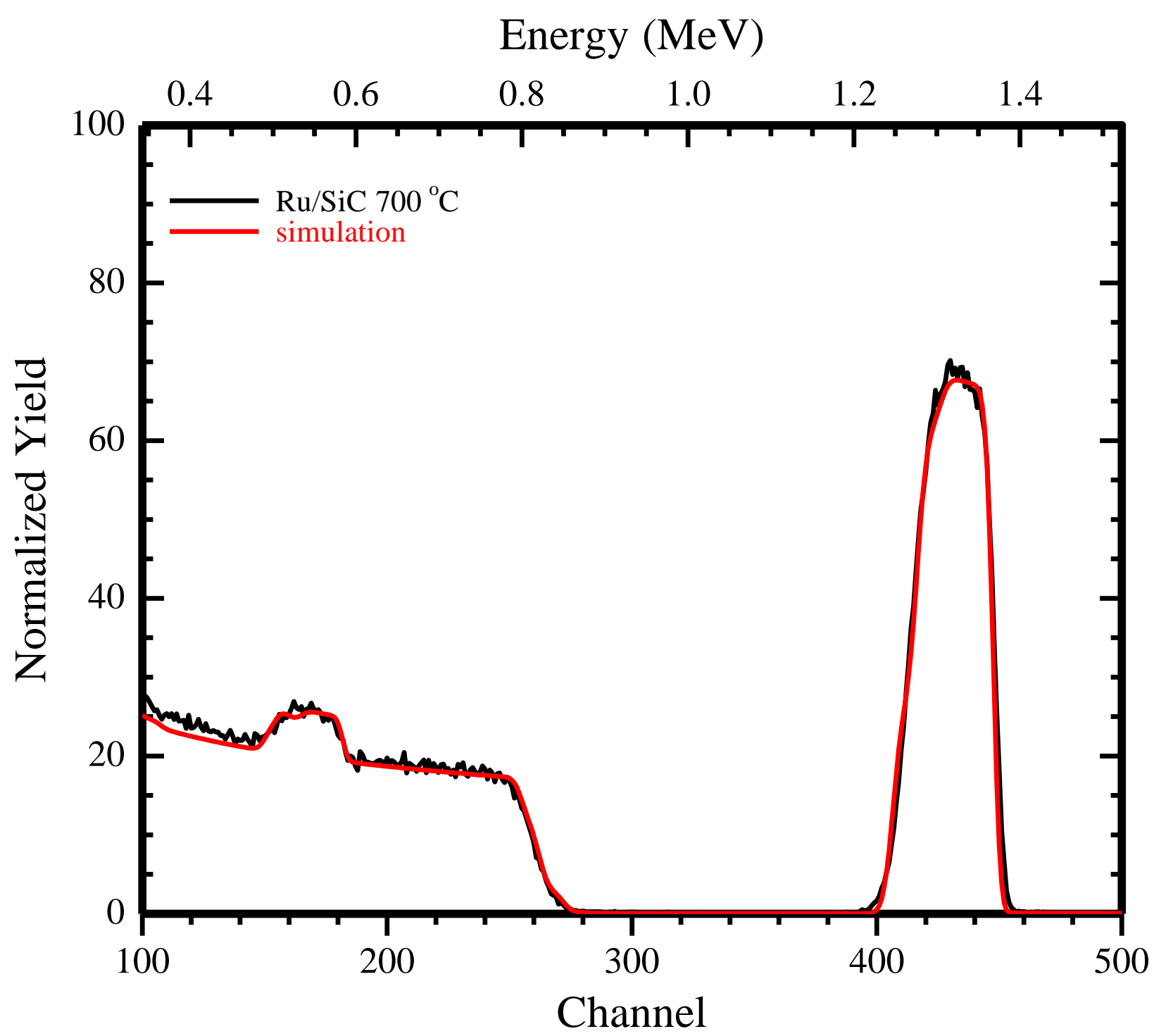

Fig. 3. RBS spectrum of thin film of Ru-6H-SiC annealed in argon at $700{ }^{\circ} \mathrm{C}$ obtained by using $1.6 \mathrm{MeV}$ helium ions.

larger oxygen peak. At $1000{ }^{\circ} \mathrm{C}$, it is observed that the interdiffusion of Ru and Si is very deep as indicated by the wide base of the Ru signal and the appearance of the Si at its surface energy position (Fig. 4).

The RBS spectra were simulated using the iterative software RUMP. The simulated spectra have been included together with raw RBS spectra (Fig1-Fig 3). The RBS charging current exhibited some instability during the analysis of the sample annealed at $1000{ }^{\circ} \mathrm{C}$, and therefore its spectrum was not simulated. The simulations were performed by varying the composition of $\mathrm{Ru}, \mathrm{Si}, \mathrm{C}$ and $\mathrm{O}$ in a layer-by-layer manner to obtain a good fit. From these simulated spectra, the composition profiles were obtained. It can be observed that the simulated spectra fit well with the raw spectra which indicates that the simulations are a good representation of 


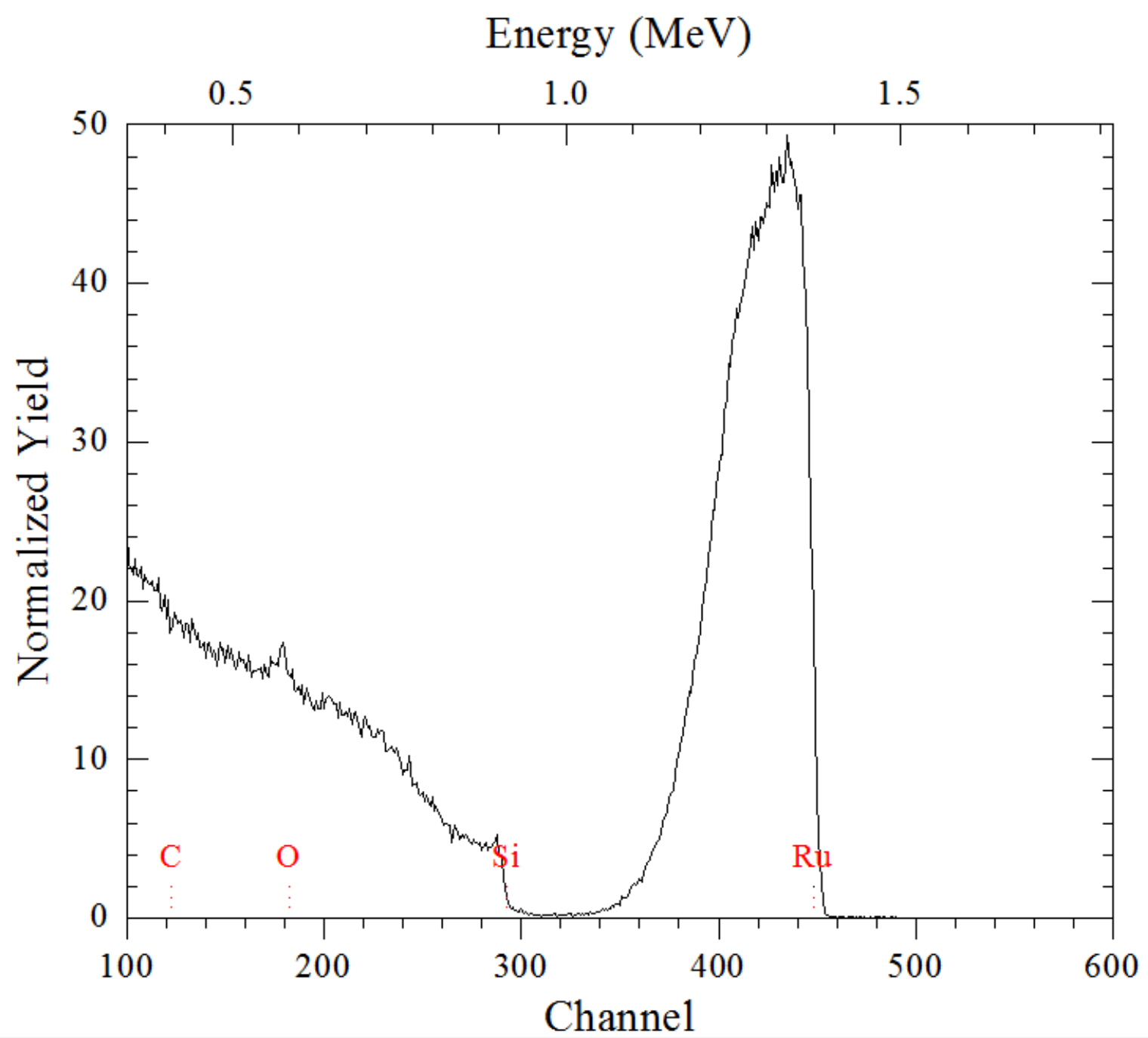

Fig. 4. RBS spectrum of thin film of $\mathrm{Ru}-6 \mathrm{H}-\mathrm{SiC}$ annealed in argon at $1000{ }^{\circ} \mathrm{C}$ obtained by using $1.6 \mathrm{MeV}$ helium ions. 


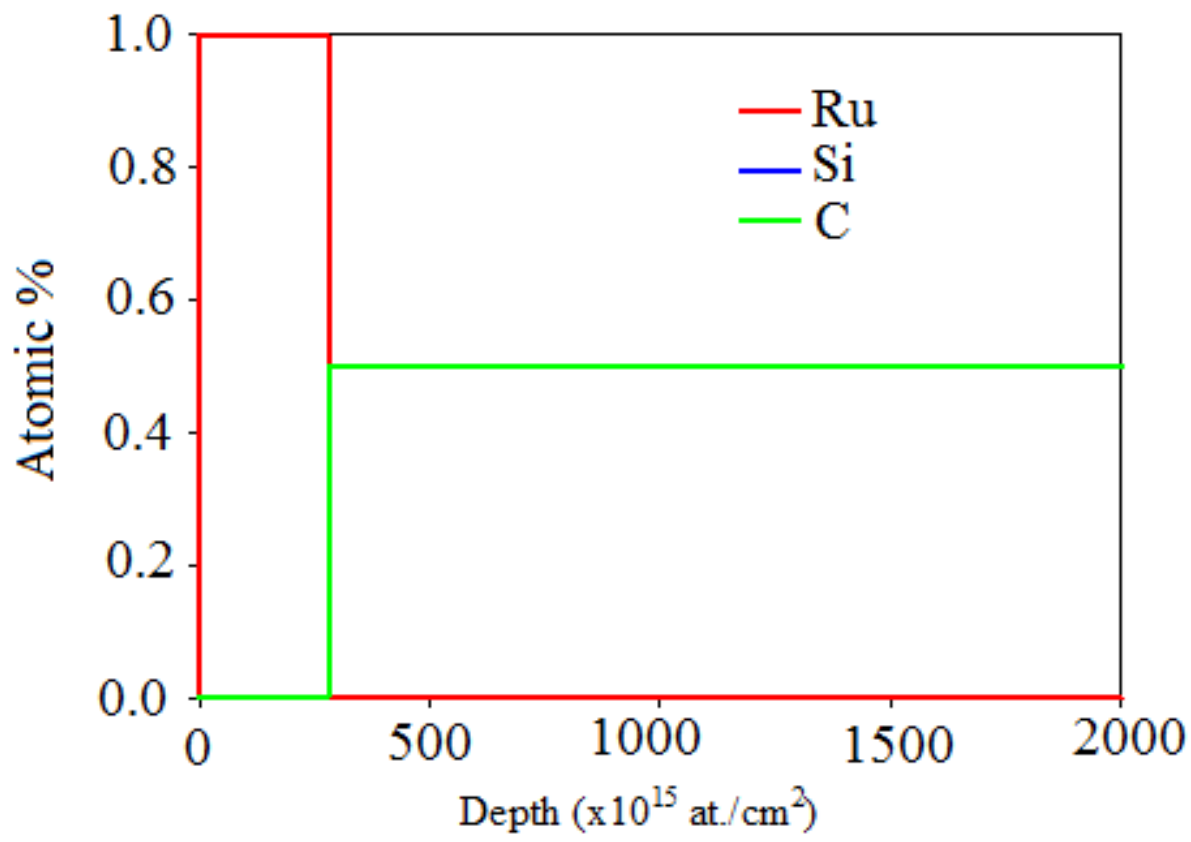

Fig. 5. Depth profile of as-deposited $\mathrm{Ru}-6 \mathrm{H}-\mathrm{SiC}$

the raw RBS spectra. These simulations show that the as-deposited Ru-6H-SiC interface is located at $280 \times 10^{15}$ at $/ \mathrm{cm}^{2}$ (Fig. 5). Oxidation and minimal Ru, Si and C interdiffusion begin at an annealing temperature of $500{ }^{\circ} \mathrm{C}$ (Fig. 6). Oxidation and elements interdiffusion are observed to increase with annealing temperature (Fig .7 and Fig. 8), such that Ru is found at a depth of $1100 \times 10^{15} \mathrm{at} . / \mathrm{cm}^{2}$ and $1380 \times 10^{15} \mathrm{at} . / \mathrm{cm}^{2}$ at annealing temperatures of $700{ }^{\circ} \mathrm{C}$ and $900{ }^{\circ} \mathrm{C}$ respectively.

SEM was used to analyse the as-deposited thin film sample and the sample annealed at $500{ }^{\circ} \mathrm{C}$ to identify structural changes that took place during the annealing process. From the SEM images one can clearly see that the as-deposited thin film (Fig. 9) of Ru is rough, disorderly and therefore amorphous, while the sample annealed at $500{ }^{\circ} \mathrm{C}$ (Fig. 10) is smooth which is an indication of the improvement in the grain quality of Ru or the microcrystalline nature of the ruthenium oxide $\left(\mathrm{RuO}_{2}\right)$ formed during the annealing process. 


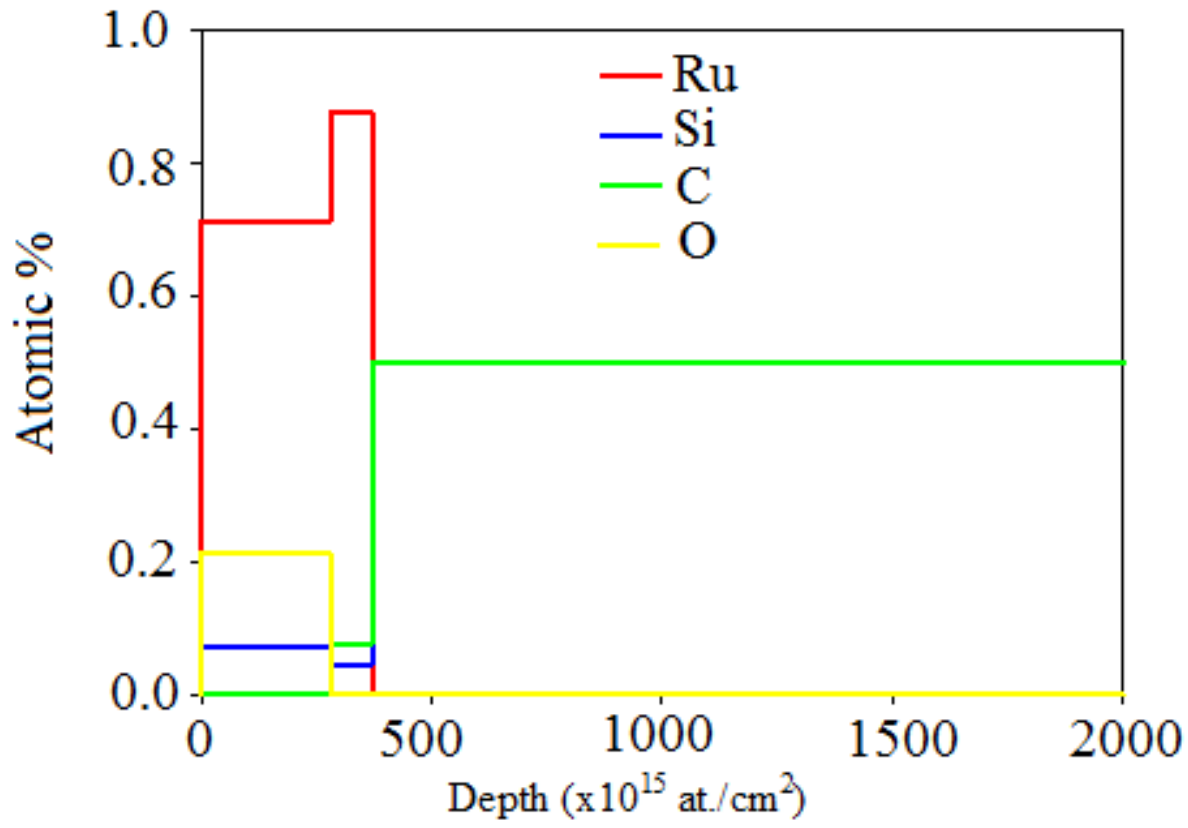

Fig.6. Depth profile of Ru-6H-SiC annealed in $\operatorname{argon}$ at $500{ }^{\circ} \mathrm{C}$

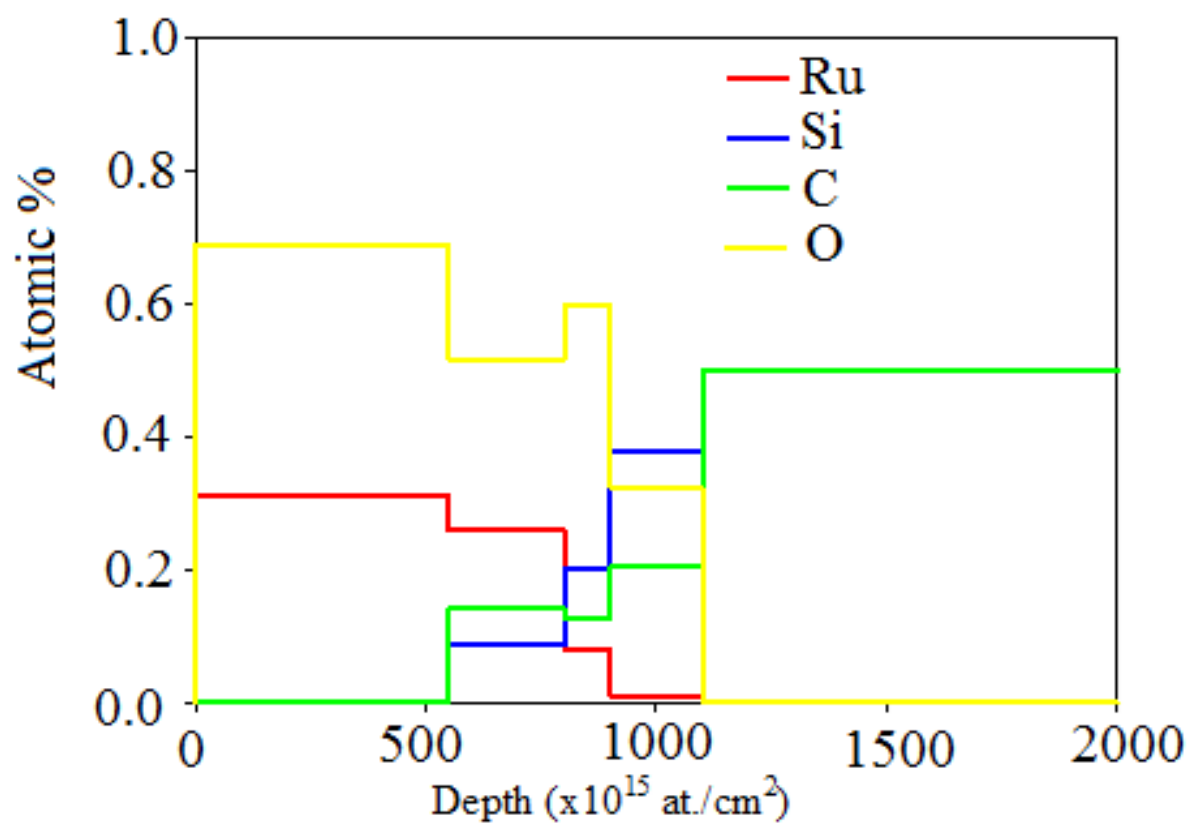

Fig.7. Depth profile of Ru-6H-SiC annealed in argon at $700{ }^{\circ} \mathrm{C}$ 


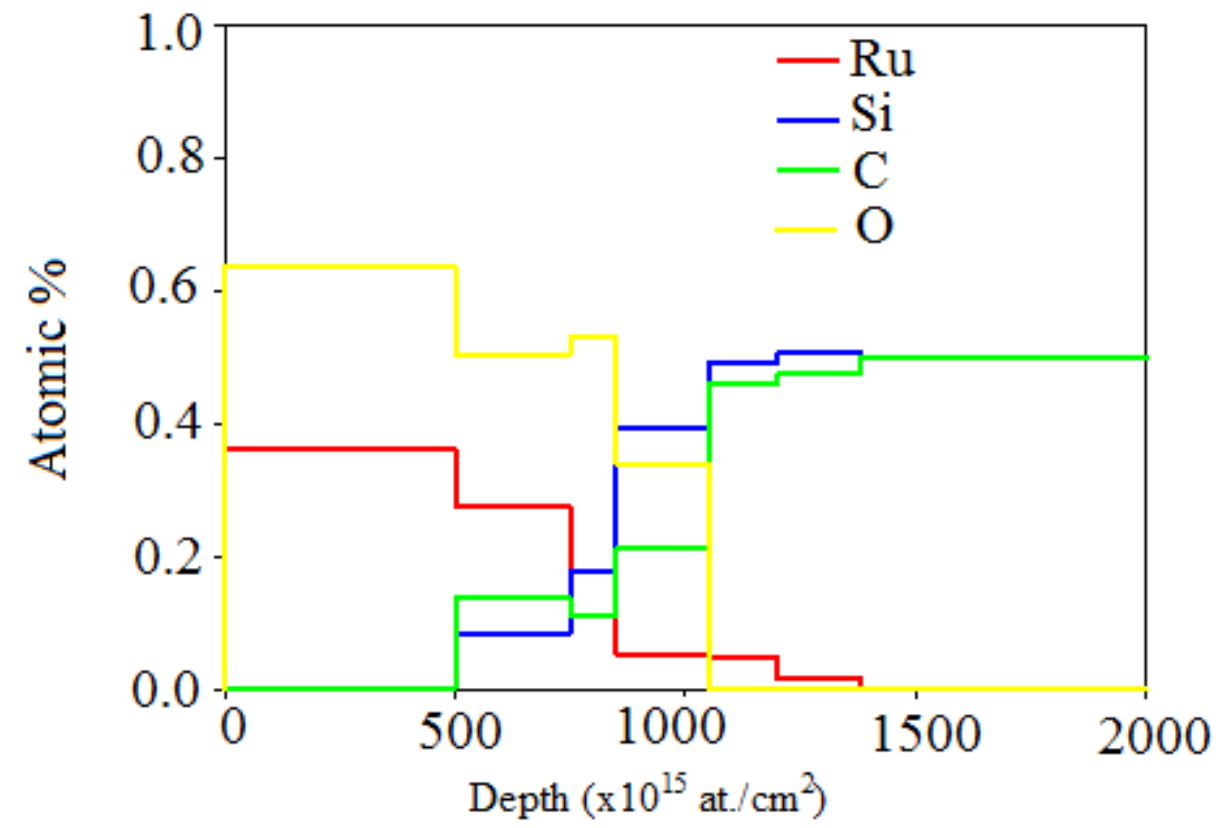

Fig.8. Depth profile of $\mathrm{Ru}-6 \mathrm{H}-\mathrm{SiC}$ annealed in argon at $900{ }^{\circ} \mathrm{C}$

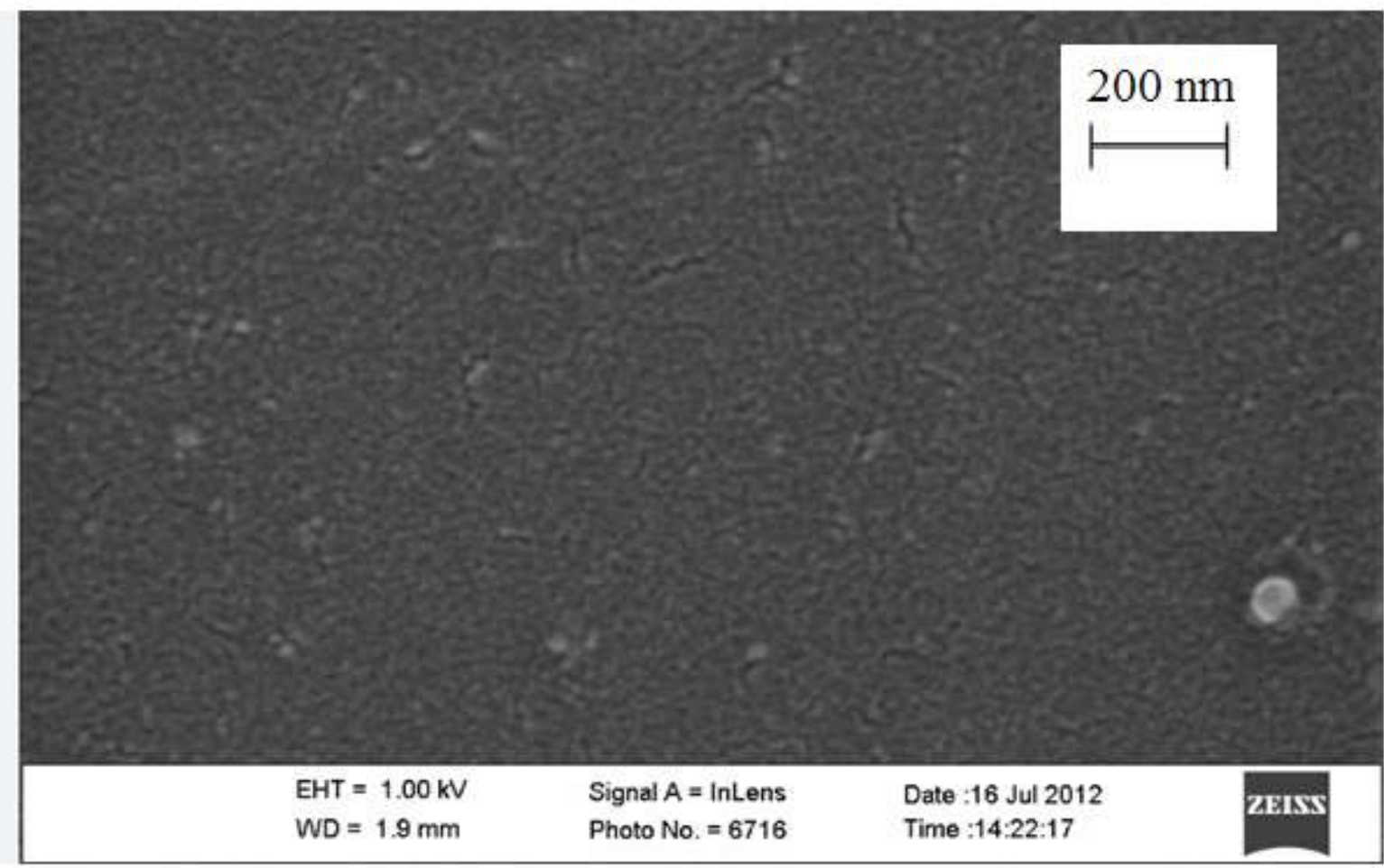

Fig. 9. SEM image of as-deposited thin film of Ru-6H-SiC 


\section{$100 \mathrm{~nm}$}
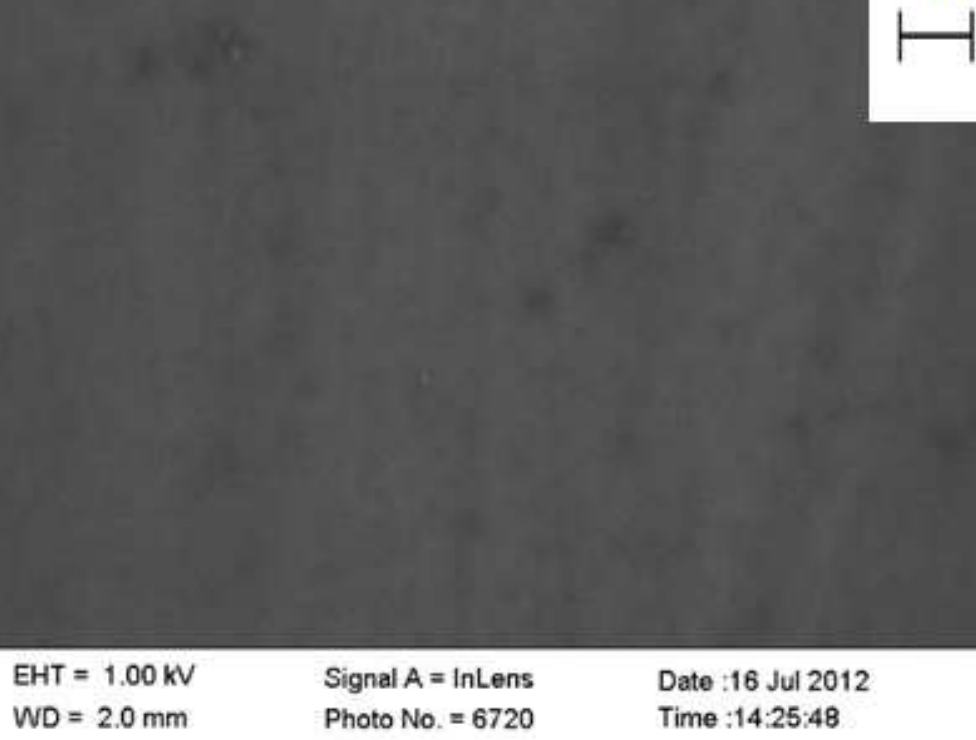

Fig. 10. SEM image of thin film of ruthenium on $6 \mathrm{H}-\mathrm{SiC}$ annealed in argon at $500{ }^{\circ} \mathrm{C}$.

The Ru-6H-SiC Schottky diodes were evaluated using IV and CV characteristics. The Schottky barrier height $(\mathrm{SBH}), \phi_{B n}$, ideality factor, $\eta$, and reverse saturation current $\mathrm{I}_{\mathrm{S}}$ were obtained from IV characteristics by assuming that the Schottky diode obeys the thermionic emission model [9] given by equation (1) below.

$$
J=J_{s}\left(e^{\frac{q V}{\eta k T}}-1\right)
$$

where

$$
J_{s}=A^{*} T^{2} \mathrm{e}^{-\frac{q \phi_{B}}{k T}}
$$

where $J_{s}$ is the reverse saturation current density, T is absolute temperature in Kelvin, $\mathrm{k}$ is the Boltzmann constant, $\mathrm{q}$ is the absolute amount of charge on an electron, and $A^{*}$ is the Richardson constant which is equal to $72 \mathrm{Acm}^{-2} \mathrm{~K}^{-2}$ for $6 \mathrm{H}-\mathrm{SiC}$.

Series resistance $R_{S}$ is the resistance of the bulk material of the semiconductor plus that of the back ohmic contact. To account for the series resistance equation (1) is modified to the following equation 
$J=J_{s}\left[e^{\frac{q_{(V-I R S)}}{\eta k T}}-1\right]$

The parameters from CV characteristics are obtained from the junction capacitance of the SBD [9] given by

$C=\sqrt{\frac{q \varepsilon_{s} N_{D}}{2\left(V_{b i}-V\right)}}$

$\frac{1}{C^{2}}=\frac{2\left(V_{b i}-V\right)}{q \varepsilon_{s} N_{D}}\left(F c m^{-2}\right)^{-2}$

A plot of $\frac{1}{C^{2}}$ versus $\mathrm{V}$ will give a straight line, and a donor doping density $N_{D}$ can be extracted from the graph. The SBH is determined from the voltage intercept by the following equation

$$
\phi_{B n}=V_{i}+V_{o}
$$

where $\mathrm{V}_{\mathrm{i}}$ is the voltage intercept, and

$$
V_{O}=\frac{k T}{q} \ln \left(\frac{N_{C}}{N_{D}}\right)
$$

where $\mathrm{N}_{\mathrm{C}}$ is the effective density of states in the conduction band of $6 \mathrm{H}-\mathrm{SiC} . \mathrm{N}_{\mathrm{C}}$ is equal to $8.9 \times 10^{19} \mathrm{~cm}^{-3}$ for $6 \mathrm{H}-\mathrm{SiC}$ at $300 \mathrm{~K}[10]$.

Table I shows the parameters that were extracted after annealing the $\mathrm{Ru}-6 \mathrm{H}-\mathrm{SiC}$ diodes in argon.

According to Table I, that the ideality factor and SBH (obtained from IV characteristics) show very small variation with increasing annealing temperature. The fact that the ideality factor is slightly higher than the ideal value may be attributed to current flow not being by thermionic emission only, some tunnelling effects and recombination currents might be involved as well.

The SBHs obtained from CV characteristics were slightly higher than those from IV characteristics. Normally SBH obtained from CV measurements are slightly higher than those obtained from IV characteristics because there might be an additional capacitance at the metal-semiconductor interface due to the presence of a thin oxide, which develops as a result of surface preparation [10]. The variation of SBH as observed in the table may be attributed to the presence of an inhomogeneous barrier at the metal semiconductor interface. According to Osvald et al [11], SBH inhomogeneity may be due to the fact that there are different crystallographic 
Table I. Parameters of Ru-6H-SiC schottky diodes at various annealing temperature

\begin{tabular}{|c|c|c|c|c|c|c|}
\hline $\begin{array}{l}\text { Annealing } \\
\text { temperature }\end{array}$ & $\begin{array}{c}\text { Ideality } \\
\text { factor }(\eta)\end{array}$ & $\begin{array}{c}\text { SBH from } \\
I-V(\mathbf{e V})\end{array}$ & $\begin{array}{c}\text { SBH from } \\
C-V(e V)\end{array}$ & $\begin{array}{c}\text { Series } \\
\text { resistance } \\
R_{\mathrm{s}}(\Omega)\end{array}$ & $\begin{array}{c}\text { Saturation } \\
\text { current } I_{S}(A)\end{array}$ & $\begin{array}{c}\text { Donor density } \\
N_{D}\left(\mathrm{~cm}^{-3}\right)\end{array}$ \\
\hline As dep & 2.77 & 0.807 & 0.629 & 187.93 & $7.39 \times 10^{-10}$ & $1.62 \times 10^{18}$ \\
\hline $100^{\circ} \mathrm{C}$ & 2.165 & 0.784 & 0.582 & 174.87 & $1.8 \times 10^{-9}$ & $2.24 \times 10^{18}$ \\
\hline $200^{\circ} \mathrm{C}$ & 1.876 & 0.746 & 0.808 & 410.23 & $8.1 \times 10^{-9}$ & $2.85 \times 10^{18}$ \\
\hline $300^{\circ} \mathrm{C}$ & 1.995 & 0.775 & 0.986 & 461.79 & $2.55 \times 10^{-9}$ & $2.45 \times 10^{18}$ \\
\hline $400^{\circ} \mathrm{C}$ & 1.83 & 0.718 & 0.823 & 291.76 & $2.39 \times 10^{-8}$ & $2.73 \times 10^{18}$ \\
\hline $500^{\circ} \mathrm{C}$ & 1.655 & 0.757 & 0.94 & 461.79 & $5.11 \times 10^{-9}$ & $1.97 \times 10^{18}$ \\
\hline $600^{\circ} \mathrm{C}$ & 1.949 & 0.734 & 0.544 & 47.18 & $1.29 \times 10^{-8}$ & $2.79 \times 10^{18}$ \\
\hline $700^{\circ} \mathrm{C}$ & 1.616 & 0.847 & 0.639 & 113.63 & $1.53 \times 10^{-10}$ & $2.47 \times 10^{18}$ \\
\hline $800^{\circ} \mathrm{C}$ & 1.576 & 0.948 & 0.957 & 666.77 & $3.02 \times 10^{-12}$ & $2.35 \times 10^{18}$ \\
\hline $900^{\circ} \mathrm{C}$ & 2.05 & 1.167 & 1.827 & 578.58 & $5.78 \times 10^{-16}$ & $1.86 \times 10^{18}$ \\
\hline
\end{tabular}


orientations of the grains in the polycrystalline structure of the metallic layer and there is also a possibility that the phase composition of the interface materials may change after annealing. Both arguments are highly applicable to this investigation as there is evidence, from RBS analysis, of formation of $\mathrm{RuO}_{2}$ and $\mathrm{Ru}$ and $\mathrm{Si}$ interdiffusion at the interface at higher annealing temperatures as explained above. From the SEM images there is evidence of a change in the crystallinity of the $\mathrm{Ru}$ at higher annealing temperatures.

The series resistance exhibited some randomness in value after each annealing temperature. This randomness in the value of series resistance is supported by investigations of Chand [12], who in his research paper found that there is a random variation of series resistance of elementary diodes in inhomogeneous Schottky diodes. At $600{ }^{\circ} \mathrm{C}$, the series resistance is observed to decrease to a low value of $47 \Omega$. RBS analysis of the thin $\mathrm{Ru}-6 \mathrm{H}-\mathrm{SiC}$ film has indicated the formation of $\mathrm{RuO}_{2}$ at this temperature. The $\mathrm{SBH}$ of $\mathrm{RuO}_{2}$ on $\mathrm{SiC}$ of $0.88 \mathrm{eV}$ [1] does not explain this change in resistance. A comparison of the electrical resistivities of $\mathrm{Ru}$ and $\mathrm{RuO}_{2}$, which are $7.4 \mu \Omega \mathrm{cm}$ (polychrystalline) and $35.2 \mu \Omega \mathrm{cm}$ respectively, does not offer a plausible explanation of the decrease of series resistance as well. Jelenkovic et al [13] similarly observed the reduction of resistivity of Ru deposited on silicon after annealing at $400{ }^{\circ} \mathrm{C}$ in nitrogen, and they attributed the drop in resistivity to the improvement in grain quality of Ru films. The decrease in series resistance can be attributed to the improvement in the grain quality of $\mathrm{Ru}$ or the microcrystalline nature of the $\mathrm{RuO}_{2}$ formed during the annealing process, as evidenced by the SEM images.

One can also note that there was little variation in $\mathrm{SBH}$ even after the formation of $\mathrm{RuO}_{2}$. One possible explanation of the small change in $\mathrm{SBH}$ variation is that the $\mathrm{SBH}$ of $\mathrm{RuO}_{2}$ on $\mathrm{SiC}$ of $0.88 \mathrm{eV}$ [14] is very close to the SBH of $\mathrm{Ru}$ on $\mathrm{SiC}$.

A plot of $\frac{1}{C^{2}}$ vs reverse voltage (Fig. 11) exhibits excellent linearity from the as-deposited diodes to the diodes annealed at the final annealing temperature of $900^{\circ} \mathrm{C}$. The linearity indicates the operational stability of the Schottky diodes at extremely high annealing temperatures. The doping density $\mathrm{N}_{\mathrm{D}}$ extracted from $\mathrm{CV}$ characteristics shows a slight variation at different annealing temperatures. This variation might be due to the variation in series resistance. According to Frojdh et al [15] a resistance in series with a capacitor makes the 


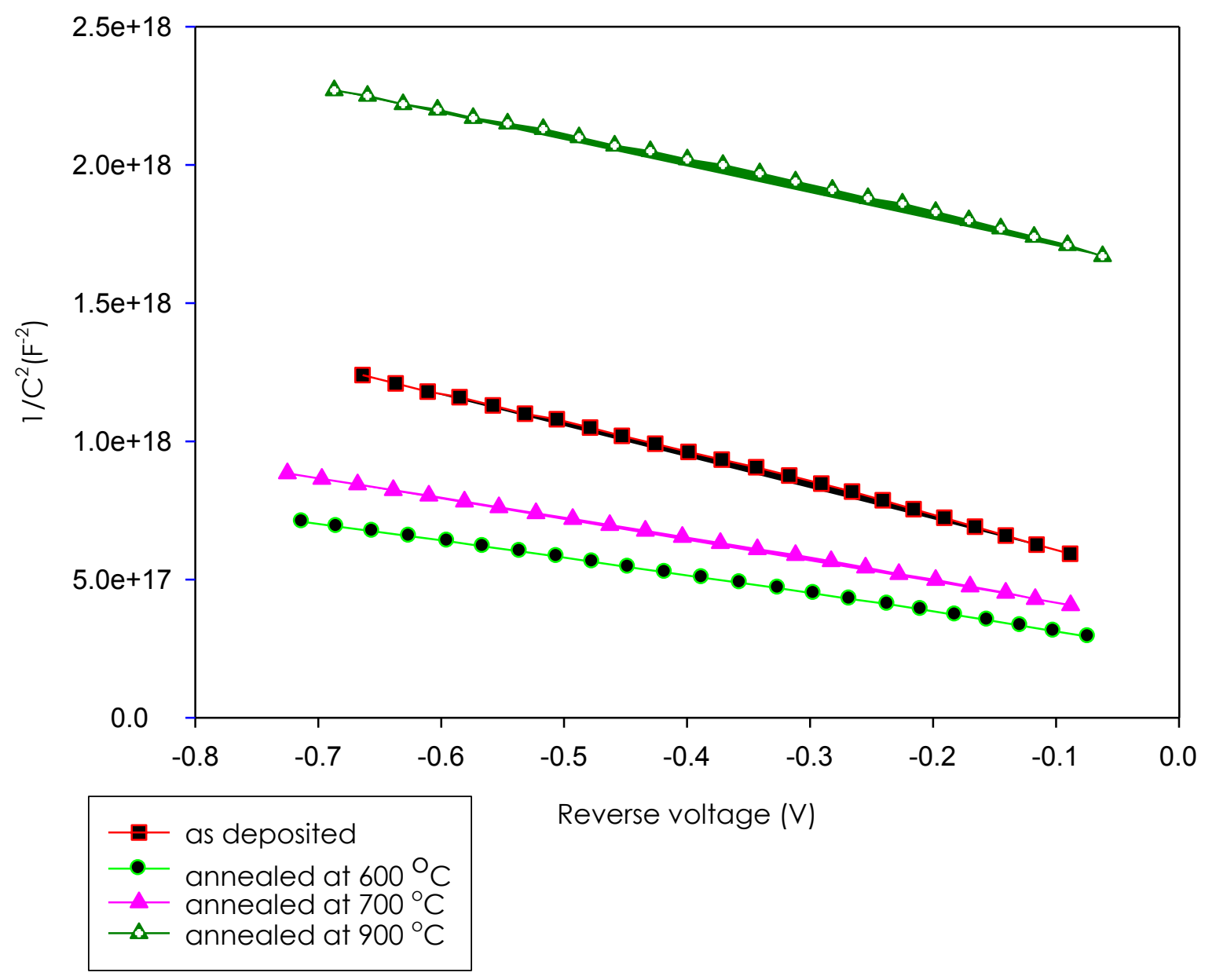

Fig. 11. A plot of $1 / \mathrm{C}^{2}$ vs reverse voltage for $\mathrm{Ru}-6 \mathrm{H}-\mathrm{SiC}$ SBDs annealed at various temperatures in argon

measured value of capacitance to decrease. From this assertion, an increase in series resistance will lead to a decrease in the capacitance measured. In this investigation the series resistance showed some randomness in its values which led to the variation of the capacitance which in turn led to the variation in the donor density extracted from the CV curves. Using equation (4) one gets

$N_{D}=\frac{2\left(V_{b i}-V\right) C^{2}}{q \varepsilon_{s}}$

When comparing the values of series resistance and donor density in Table I, and then linking the values with equation (8), one should observe that for high values of resistance, the capacitance measured will be low and therefore $N_{D}$ values extracted from the equation should be low as well. The data in Table I largely agrees with this view. 
Furthermore the plot of $1 / C^{2}$ vs reverse voltage will give the space charge density in the depletion layer corresponding to the dopants that are electrically active. If the dopants are not electrically active (i.e have not ionised) then this method will not correctly find the dopant density [15]. The factory specification of $N_{D}$ for the $6 \mathrm{H}-\mathrm{SiC}$ wafer that was used in this investigation is $9 \times 10^{14}-1 \times 10^{19} \mathrm{~cm}^{-3}$. The results of $N_{D}$ obtained in the investigation are well within the range of the specification.

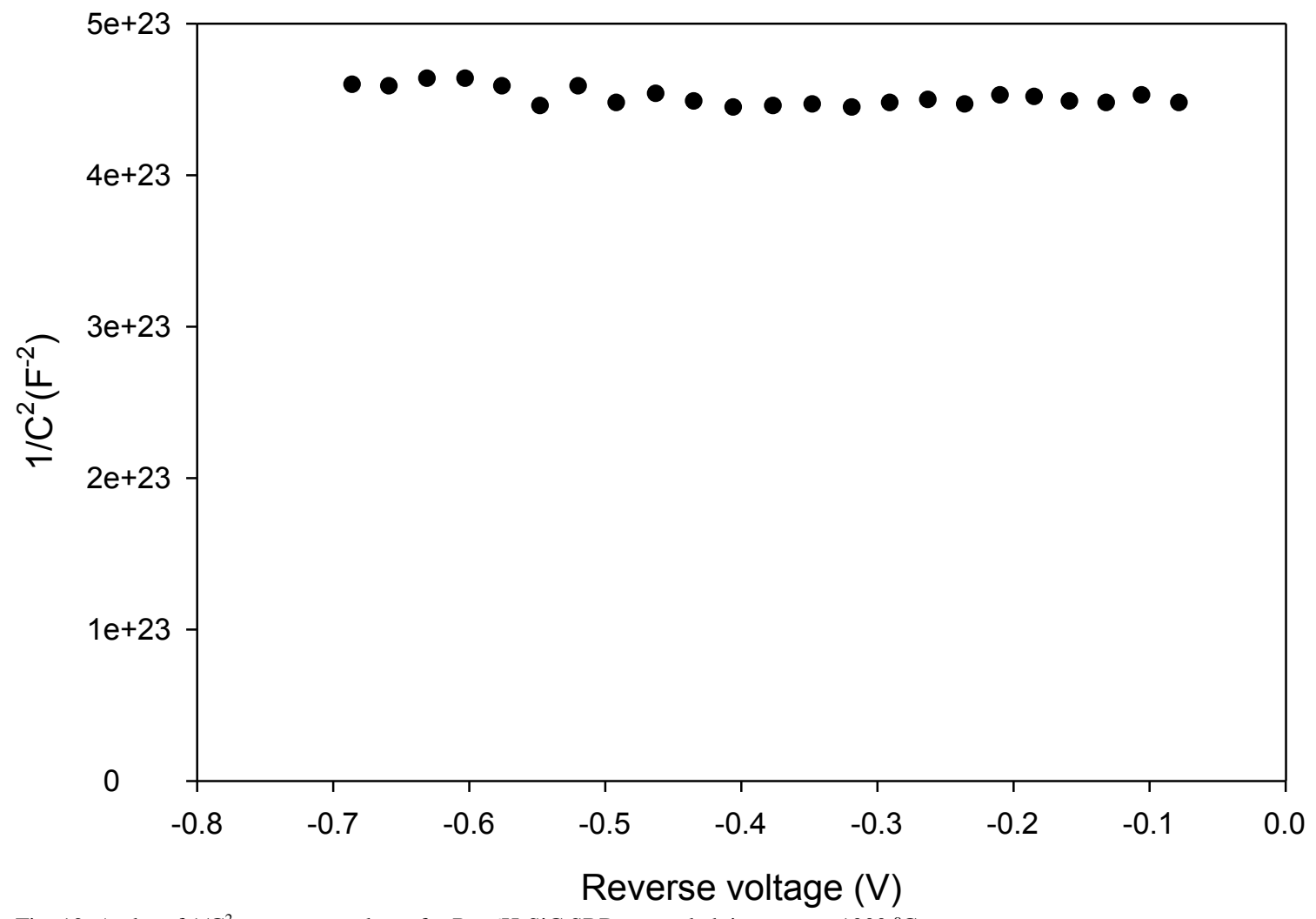

Fig. 12. A plot of $1 / \mathrm{C}^{2}$ vs reverse voltage for Ru-6H-SiC SBDs annealed in argon at $1000{ }^{\circ} \mathrm{C}$

The forward IV characteristic for the Schottky diodes (Fig. 13) showed good rectification behaviour. The Ru$6 \mathrm{H}-\mathrm{SiC}$ schottky diodes degraded when they were annealed at $1000{ }^{\circ} \mathrm{C}$ as evidenced by a non-linear $\mathrm{CV}$ graph (Fig 12). Fig 12 was plotted separately from Fig 11 because the inverse square values of capacitance were very much larger at $1000{ }^{\circ} \mathrm{C}$ than at other annealing temperatures. The degradation of the Schottky diode can be attributed to the deterioration of the $\mathrm{Ru}$ Schottky contact due to the inter-diffusion of $\mathrm{Ru}$ and $\mathrm{Si}$ at the $\mathrm{Ru}-6 \mathrm{H}-$ $\mathrm{SiC}$ interface as indicated by RBS analysis of the sample (Fig. 4) at $1000{ }^{\circ} \mathrm{C}$. 


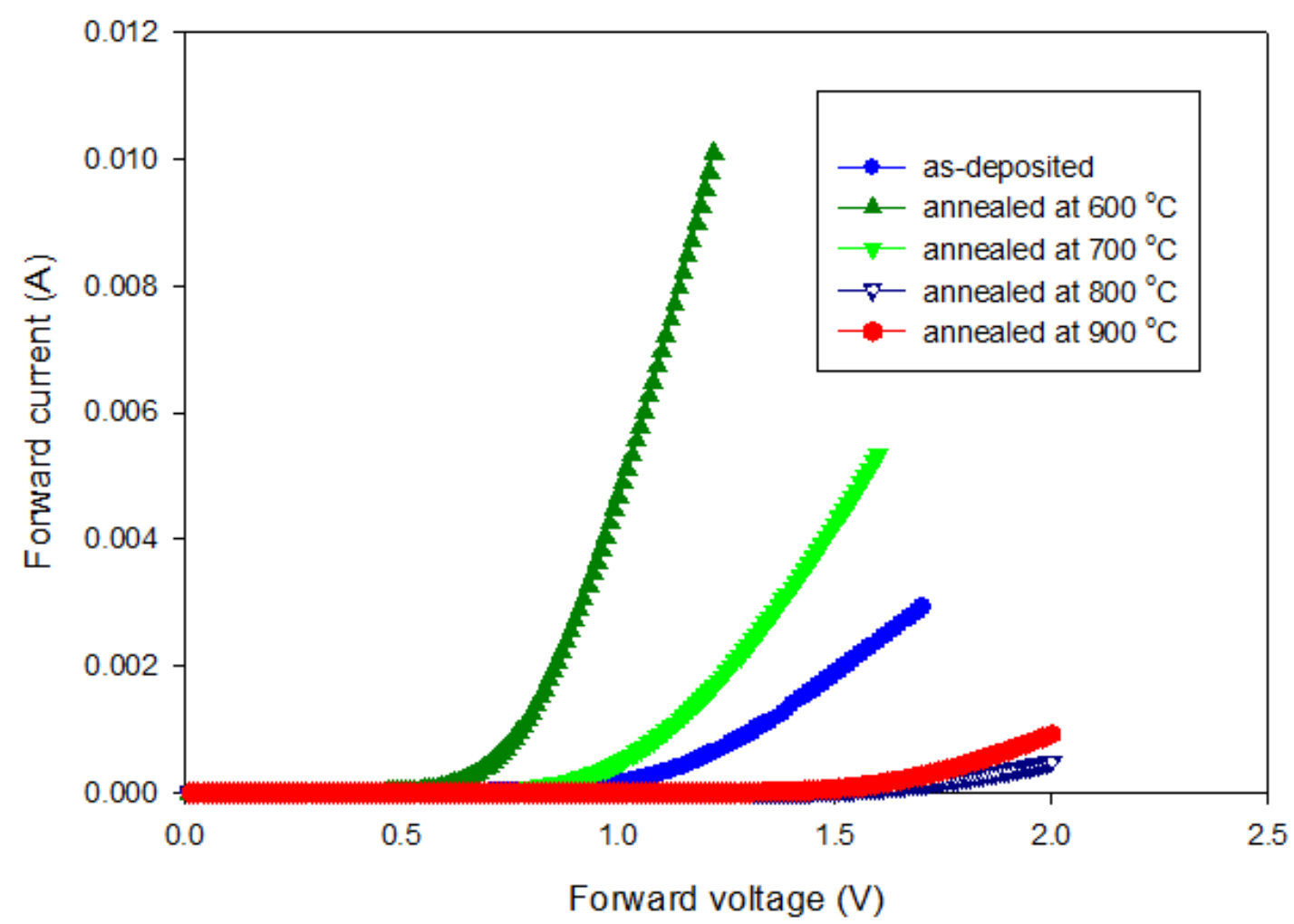

Fig. 13. Graph of forward IV characteristics for $\mathrm{Ru}-6 \mathrm{H}-\mathrm{SiC}$ SBDs annealed in argon at various temperatures

\section{Conclusion}

The Ru-6H-SiC Schottky diodes that were fabricated showed excellent rectifying behaviour by exhibiting linear $\mathrm{CV}$ characteristics and exponential IV characteristics up to the final annealing temperature of $900{ }^{\circ} \mathrm{C}$. From the data obtained in this investigation, annealing the SBDs in argon at a temperature of $600{ }^{\circ} \mathrm{C}$ gives the lowest series resistance of the SBDs. The investigation has shown that $6 \mathrm{H}-\mathrm{SiC}$ without an epilayer is able to produce excellent Schottky diodes which can operate at extremely high temperatures. The degradation mechanism of the Schottky diodes has been shown to be the inter-diffusion of $\mathrm{Ru}$ and $\mathrm{Si}$ at the $\mathrm{Ru}-\mathrm{SiC}$ interface.

\section{References}

[1] L. Stuchlikova, D. Buc, L. Harmatha, U. Helmersson, W. H. Chang, I. Bello, Appl. Phys. Lett. 88, 153509 (2006)

[2] D. Buc, L. Stuchlikova, U. Helmersson, W.H. Chang.,I. Bello, Chem. Phys. Lett. 429, 617-621 (2006) 
[3] D. Buc, L. Stuchlikova, L. Harmatha, I. Hotovy, J Mater Sci: Mater Electron. 19:783-787 (2008)

[4] S. Roy, C. Jacob , M.Zhang, S. Wang, A.K. Tyagi , S. Basu , Appl. Surf. Sci. 211 300-307 (2003)

[5] A. Venter, M.E.Samiji , A.W.R.Leitch, phys. stat. sol. (c) 1, No. 9, 2264- 2268 (2004)

[6] A. Venter, M.E. Samiji, A.W.R. Leitch, Diamond Relat. Mater.13 (2004) 1166-1170 (2004)

[7] K.V. Munthali, C. Theron, F.D. Auret, S.M.M. Coelho, E. Njoroge, L. Prinsloo, Mater. Sci. Eng., B181, 9-15 (2014)

[8] F. La Via , F. Roccaforte, A. Makhtari, V. Raineri , P. Musumeci ,L. Calcagno, Microelectron. Eng. 60, 269-282 (2002)

[9] S.M. Sze, Semiconductor Devices Physics Technology, 2nd edn. , (John Wiley \& Sons, New York, 2002) pp. $90-114$

[10] Ioffe Institute, New Semiconductor Materials-Characteristics and Properties,

http://www.ioffe.rssi.ru/SVA/NSM/Semicond/SiC/bandstr.html, accessed 25 April 2013

[11] J. Osvaldy, E. Dobrockaz, Semicond. Sci. Technol.1198-1202 (1996)

[12] S. Chand, Physica B 373 284-290 (2005)

[13] E.V. Jelenkovic, K .Y. Tong, W. Y. Cheung, S. P. Wong, Semicond. Sci. Technol. 18 454-459 (2003)

[14] E. Stuchlikova, L. Harmatha, D. Buic, J. Benkovska, B. Hlinka, G. G. Siu, IEEE. (2006)

[15] C. Frojdh, G.Thungstrom, H.E. Nilsson, C.S. Petersson, Phys. Scr. Vol. T79, pp. 297-302, (1999) 